\title{
EMPREENDEDORISMO E O DESENVOLVIMENTO: REVISÃO BIBLIOGRÁFICA
}

Michele Raasch $^{1}$

Mario Canever ${ }^{1}$

${ }^{1}$ Universidade Federal de Pelotas 


\section{EMPREENDEDORISMO E O DESENVOLVIMENTO: REVISÃO BIBLIOGRÁFICA}

Resumo: Considerando que o empreendedorismo pode ser um elemento fundamental para o desenvolvimento sócio-econômico, o presente estudo possui o objetivo de realizar um levantamento bibliométrico de pesquisas relacionadas a empreendedorismo $\mathrm{e}$ desenvolvimento na base de dados SPELL, a fim de contemplar e disseminar os periódicos brasileiros. A amostra analisada foi composta por 30 artigos, do período de 2003 até 2017, onde o empreendedorismo é estudado sob óticas distintas de geração de desenvolvimento, porém em alguns estudos não é encontrada tal relação. Dentre os resultados a Revista de Empreendedorismo e Gestão de Pequenas Empresas foi a que mais publicou sobre o tema. Já o autor Louis Jacques Filion foi o mais referenciado nos artigos, e o trabalho mais referenciado foi o livro de Joseph Alois Schumpeter "A teoria do desenvolvimento econômico". Também foram identificadas a composição de redes e parcerias de autores na elaboração de artigos.

Palavras-chave: Empreendedorismo. Desenvolvimento. Bibliométrica. 


\section{Introdução}

A literatura destaca que o empreendedorismo atrai a atenção de pesquisadores pelo impacto que provoca na sociedade, como o crescimento econômico, a geração de empregos, (BARINI FILHO; CARDOSO, 2003; AUDRETSCH, et al. 2008; FONTENELE; MOURA; LEOCADIO, 2011; LINAAN; RODRIGUEZ-COHARD; RUEDA-CANTUCHE， 2011; SANCHEZ, 2011; SARFATI, 2013; VERGA; SILVA, 2014), no aumento da produtividade local, na inovação (OCDE, 2007). O termo empreendedorismo é considerado complexo, não devendo ser analisado por apenas uma área (VERGA; SILVA, 2014). Segundo a pesquisa GEM (2009) - Global Entrepreneurship Monitor-, a qual considera o empreendedorismo como o principal propulsor do crescimento econômico, o empreendedorismo é toda e qualquer tentativa de criação de um novo negócio.

O empreendedorismo pode ocorrer por dois motivos, pela oportunidade de um novo negócio, o qual possui um maior impacto no crescimento econômico de onde está localizado, e pela necessidade do aumento da renda familiar (GEM, 2009). Ele ainda pode ser caracterizado como empreendedorismo social, concentrando suas forças em ações sociais, ao invés da riqueza, possuindo mesmo assim características semelhantes de um empreendedor tradicional (ELKINGTON; HARTIGAN, 2008; FISCHER; COMINI, 2012). Já o empreendedorismo sustentável surge com proposições ambientais e sociais (MAJID; KOE, 2012; BOSZCZOWSKI; TEIXEIRA, 2012; ORSIOLLI; NOBRE, 2015).

O crescimento econômico é visto como uma das premissas necessárias para a redução da pobreza do mundo, porém é preciso o cuidado de que este crescimento ocorra de forma sustentável, focando no problema da redução da pobreza, levando em consideração o que será deixado para as gerações futuras (DEGEN, 2008). Os autores Fontenele, Moura, Leocadio (2011) afirmam que o empreendedorismo é um fator importante para o progresso econômico de determinada região. Porém muitos destes empreendimentos ainda estão na informalidade, ou seja, não estão regulamentados perante o Estado, o que acarreta além de danos econômicos grandes riscos para o trabalhador (BENNETT; GOULD; RABLEN, 2012).

Com a finalidade de identificar as publicações acerca da relação dos temas empreendedorismo e o desenvolvimento, este artigo tem por objetivo realizar uma análise quantitativa, utilizando a técnica bibliométrica, dos artigos publicados na biblioteca do Spell. Para o autor Martin (2011) a bibliometria tem contribuído para uma mudança no modo de produção do conhecimento científico. Neste artigo foram considerados os diversos tipos de empreendedorismo como o sustentável, o social, o privado, assim como as diversas formas de desenvolvimento, como econômica, social, sustentável.

A relevância deste estudo está fundamentada na importância que é atribuída para o empreendedorismo como fator do desenvolvimento econômico e social, que poderá contribuir para o desenvolvimento de políticas locais direcionadas. Portanto, saber quem, o quanto, e onde se está escrevendo sobre o assunto é fundamental para orientar os estudiosos e praticantes destas temáticas e agilizar o acréscimo de conhecimentos na área.

$\mathrm{O}$ artigo contribui com o desenvolvimento da literatura a respeito das temáticas, salientando os diferentes achados em diversas pesquisas, contribui ainda com os demais pesquisadores, uma vez que reúne e apresenta os artigos presentes na base de dados SPELL, tornando as pesquisas sobre a relação dos temas mais assertiva. A inovação da pesquisa

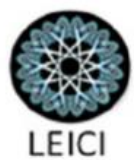


encontra-se na utilização da base de dados SPELL para seleção dos artigos, buscando assim compreender e apresentar os trabalhos que abordam o empreendedorismo e o desenvolvimento, com a intenção de contemplar a literatura brasileira.

\section{Referencial Teórico}

Nesta seção será apresentado e discutido primeiramente o construto empreendedorismo e posteriormente empreendedorismo como fator gerador de desenvolvimento.

\subsection{Empreendedorismo}

Conforme relatam os autores Verga e Silva (2014), entre o fim do século XVII e início do século XVIII o termo entrepreneur foi utilizado para caracterizar as pessoas que criavam e conduziam empreendimentos. Em seu estudo Landström e Benner (2010) expõe os principais autores que pregavam o empreendedorismo, como: Richard Cantillon (1680-1734), que considerava a troca de mercadorias voltada para o lucro, como empreendedorismo; Jean Baptiste Say (1767-1832) o qual considerava como empreendedor o indivíduo que combinava fatores de produção que resultavam em novos empreendimentos. Na percepção de Barini Filho e Cardodo (2003) foi McClelland (1972) o autor originário da capacidade empreendedora de um indivíduo, quando tal buscou identificar o fator comum que leva o indivíduo e as sociedades ao desenvolvimento.

A conceituação de empreendedor e empreendedorismo é diversa, para Filion (1999) o empreendedor é caracterizado por ser uma pessoa que possui criatividade, consciência ambiental, que sabe identificar oportunidades de negócios. Para Drucker (2008) o empreendedor é aquele que inicia um novo negócio, desde que este possua as características empreendedoras essenciais. Para os autores Hisrich, Peters, Shepherd (2009) existem quatro momentos no processo empreendedor: 1) identificação e avaliação da oportunidade; 2) desenvolvimento do plano de negócios; 3) determinação dos recursos necessários; 4) administração da empresa. O termo empreendedorismo é muito complexo para ser analisado por apenas um por apenas uma área, como psicologia ou por economia (VERGA; SILVA, 2014).

O termo empreendedorismo ainda é definido por Shane e Venkataraman (2000), como o estudo das fontes das oportunidades para criar algo novo (novos produtos ou serviços, novos mercados, novos processos de produção ou matérias-primas, novas formas de organizar as técnicas existentes) e o processo de descoberta, exploração e avaliação, por parte dos indivíduos que as descobrem, avaliando e explorando essas coisas novas, usando diversos meios para se atingir um fim. Em complemento Slevin e Covin (1990) consideram essenciais para o empreendedorismo elementos como correr riscos, ser proativo e a busca pela inovação.

O GEM (2009) ressalta que existe o empreendedorismo por oportunidade, o qual ocorre quando um indivíduo identifica a oportunidade de empreender. Este possui maior impacto sobre o crescimento econômico de uma região, visto que os empreendedores nesta categoria desenvolvem os negócios com inovação e tecnologia. Por outro lado, há também o empreendedorismo por necessidade, o qual ocorre quando um indivíduo empreende pela

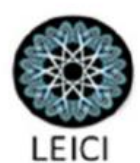


necessidade da renda. Por exemplo, uma pessoa desempregada resolve empreender para conseguir o sustento da família, o que pode levar a formação de um negócio sem distintivos competitivos e inovação, refletindo períodos de crise no país. Degen (2008) afirma que é preciso relevar o empreendedorismo por oportunidade no desenvolvimento sustentável e o empreendedorismo por necessidade na inclusão social e na redução da pobreza.

O empreendedorismo social é destacado por Fischer, Comini (2012), onde explicam que os empreendedores sociais concentram-se no impacto que a missão social terá, esta é central e explicita, ao invés da riqueza, sendo esta apenas um meio para determinado fim. Seguindo este pensamento Elkington e Hartigan (2008) ressaltam que não há como diferenciar o empreendedor social de um empreendedor privado, assim por ele chamado, visto que ambos possuem características semelhantes como inovação, percepção de oportunidades, criatividade, entre outros. Já o empreendedorismo sustentável surge como uma nova percepção dos empreendedores quanto ao uso dos recursos naturais, se preocupando com as questões ambientais e sociais (MAJID; KOE, 2012; BOSZCZOWSKI; TEIXEIRA, 2012; ORSIOLLI; NOBRE, 2015).

Segundo Fontenele, Moura, Leocadio (2011), muitos economistas afirmam que o empreendedorismo é um fator importante para o progresso econômico de determinada região. Schumpeter (1934), citado por Massaini et al., (2012), considera o empreendedor como causa primária do desenvolvimento econômico, levando a uma "destruição criadora", causando o progresso contínuo.

\subsection{Empreendedorismo X Desenvolvimento}

O empreendedorismo pode ser considerado como um fator importante para o desenvolvimento sócio-econômico, pelas oportunidades de geração de emprego que trás consigo, incubador no progresso tecnológico, entre outros fatores (MUELLER; THOMAS, 2000). Segundo exposto por Degen (2008), os empreendedores em países industrializados geraram mais riqueza que os empreendedores em países em desenvolvimento como o Brasil. Sendo o desenvolvimento local entendido como o processo de transformação econômica e do bem-estar, utilizando das potencialidades locais disponíveis (BUARQUE, 2001).

O relatório GEM (2009) deixa evidente a relação entre o empreendedorismo e o crescimento econômico. O GEM é uma pesquisa realizada desde 1999, que visa determinar as condições responsáveis pelas diferenças entre países em relação a atividade empreendedora, assim como estimar a atividade empreendedora com o crescimento econômico. Considerando como empreendedorismo qualquer tentativa de criação de um novo negócio.

Alguns trabalhos que relacionam o empreendedorismo e o desenvolvimento são expostos no Quadro 1, porém limitam-se ao contexto regional, setorial ou empresarial na qual as pesquisas se realizaram. 
Quadro 1 - Achados de estudos: relação empreendedorismo x desenvolvimento

\begin{tabular}{|c|c|}
\hline Autor & Resultados \\
\hline $\begin{array}{l}\text { Reynolds, Storey e } \\
\text { Westhead (1994) }\end{array}$ & $\begin{array}{l}\text { A criação de empresas nos vários países é influenciada pelo } \\
\text { engajamento do governo no apoio ao empreendedorismo, } \\
\text { mediante incentivos à concepção de novos projetos de } \\
\text { empresas. }\end{array}$ \\
\hline Carree, Thurik (1996) & $\begin{array}{l}\text { A presença de pequenas e médias empresas beneficia de } \\
\text { forma mais intensa os países europeus mais desenvolvidos } \\
\text { do que os países com renda per capita mais baixa, como } \\
\text { Portugal e Espanha. }\end{array}$ \\
\hline Aghion, Howitt (2005) & $\begin{array}{l}\text { O empreendedorismo pode variar, dependendo do estágio } \\
\text { de desenvolvimento do país. }\end{array}$ \\
\hline Stel, Carree e Thurik (2005) & $\begin{array}{l}\text { A atividade empreendedora, de novos negócios, afeta o } \\
\text { crescimento econômico, mas esse efeito difere de acordo } \\
\text { com o nível de renda per capita do país. }\end{array}$ \\
\hline $\begin{array}{l}\text { Wennekers e Thurik, } \\
\text { (1999); Audrestsch e } \\
\text { Keilbach (2004); Beck, } \\
\text { Demirguç-Kunt e Levine } \\
\text { (2005); Barros e Pereira } \\
\text { (2008) }\end{array}$ & $\begin{array}{l}\text { Encontraram impacto negativo entre a relação do } \\
\text { empreendedorismo e as taxas de crescimento econômico. }\end{array}$ \\
\hline $\begin{array}{l}\text { Henrekson e Johansson } \\
(2008)\end{array}$ & $\begin{array}{l}\text { Algumas empresas de crescimento acelerado (gazelas) têm } \\
\text { um grande impacto no crescimento econômico. }\end{array}$ \\
\hline $\begin{array}{l}\text { Fontenele, Moura e } \\
\text { Leocadio (2011) }\end{array}$ & $\begin{array}{l}\text { O empreendedorismo resulta em, apenas, uma alternativa } \\
\text { de trabalho e não como uma contribuição para o } \\
\text { desenvolvimento e crescimento econômicos. }\end{array}$ \\
\hline Souza e Lopez Júnior (2011) & $\begin{array}{l}\text { O estudo mostra que todas as correlações encontradas são } \\
\text { negativas, ou seja, os países considerados na pesquisa GEM } \\
\text { como mais empreendedores, com alto índice de Total } \\
\text { Entrepreneurship Activity (TEA), são países com o IDH } \\
\text { mais baixo. }\end{array}$ \\
\hline Santos e Paula (2012) & $\begin{array}{l}\text { Como resultado a especialização tecnológica local por meio } \\
\text { de sua incubadora de negócios, favoreceu a criação e } \\
\text { sustentação de empresas de base tecnológica na região, } \\
\text { gerando desenvolvimento econômico. }\end{array}$ \\
\hline Canever e Carraro (2012) & $\begin{array}{l}\text { Os resultados mostram que um aumento na taxa de start-up } \\
\text { das empresas melhora o desempenho econômico regional } \\
\text { após um período de tempo. }\end{array}$ \\
\hline $\begin{array}{l}\text { Kuyumjian, Souza e } \\
\text { Sant'anna (2014) }\end{array}$ & $\begin{array}{l}\text { O empreendedorismo social da região estudada estimula os } \\
\text { processos do chamado desenvolvimento local (não } \\
\text { considerado como progresso). }\end{array}$ \\
\hline Orsiolli e Nobre (2015) & $\begin{array}{l}\text { Os resultados demonstram que o empreendedorismo } \\
\text { sustentável contribui para o desenvolvimento sustentável à } \\
\text { medida que proporciona condições necessárias para a }\end{array}$ \\
\hline
\end{tabular}




\begin{tabular}{|l|l|}
\hline & $\begin{array}{l}\text { criação de valores econômicos, sociais e ambientais, de } \\
\text { maneira conjunta, por meio de suas estratégias de negócios. }\end{array}$ \\
\hline Souza et al. (2016) & $\begin{array}{l}\text { Os resultados identificaram correlações positivas entre os } \\
\text { empreendedores, optantes pelo programa MEI, com os os } \\
\text { níveis de renda e índice de desenvolvimento municipal, } \\
\text { além de correlação negativa com os níveis de desemprego. }\end{array}$ \\
\hline
\end{tabular}

Fonte: Autores

Os benefícios do empreendedorismo para o crescimento e o desenvolvimento econômico ficam claros na literatura, para realizar uma análise empírica da relação é necessário obter certas informações de medidas adequadas que muitas vezes são difíceis de serem obtidas (FONTENELE; MOURA; LEOCADIO, 2011). Segundo Barros e Pereira (2008), há pelo menos quatro medidas para o empreendedorismo: 1) número de trabalhadores por conta própria, ou de proprietários de empresas; 2) novos negócios; 3) empreendedores no processo de criação do novo negócio (empreendedorismo nascente); 4) participação das pequenas empresas na produção ou no emprego.

Complementando o exposto, os autores Stel, Carree e Thurik (2005), enfatizam que o empreendedor pode afetar no desenvolvimento no momento em que introduz inovações, com novos produtos ou processos produtivos. Assim como quando assume um papel importante na evolução das indústrias, no aumento da produtividade através do aumento da competição. E também obtendo conhecimento sobre necessidades dos consumidores, buscando trabalhar mais, e de forma mais eficientemente.

O desenvolvimento sustentável é cada vez de maior interesse dos empreendedores (RAUFFLET; BRES; FILION, 2014), buscando contribuir tanto para a sociedade quanto para própria organização. Nessa perspectiva os empreendedores são vistos como agentes de mudanças, demonstrando sua preocupação para além da ideia apenas de desenvolvimento econômico, mas integrando soluções ambientais e sociais (TILLEY; YOUNG, 2009), onde os empreendimentos permitem gerar renda econômica e ao mesmo tempo gerar valor sustentável, reduzindo o impacto social e ambiental (HOCKERTS; WÜSTENHAGEN, 2010).

Um problema destacado na literatura, o qual pode comprometer o desenvolvimento de determinada localidade, é a informalidade dos novos empreendimentos, onde os novos empreendedores, sejam eles por necessidade ou por oportunidade, não estão regularizados e nem protegidos pelo Estado. O que pode acarretar em danos econômicos, e ao próprio trabalhador, pois estes possuem pouca proteção social, e estão em um cenário onde há grande mortalidade de novos empreendimentos (BENNETT; GOULD; RABLEN, 2012). Souza et al., (2016), acreditam que as políticas públicas voltadas para estes indivíduos pode ajudar na criação de empreendimentos formais.

Segundo Naudé (2011) existem duas linhas de pensamentos entre a relação do empreendedorismo e o crescimento, uma possui uma visão mais reduzida de desenvolvimento ao igualar o empreendedorismo como crescimento econômico, a produtividade ou o emprego, sendo que a criação de novos negócios e a inovação não necessariamente promovem o crescimento, onde em muitas vezes se torna o resultado do mesmo. A outra possui uma visão voltada a papéis ou funções, que inclui a realocação de recursos, o risco, o ambiente para inovação e a concorrência.

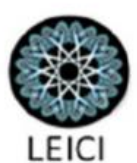


O empreendedor é visto como fundamental para o desenvolvimento econômico, criando postos de trabalho, inovando, e proporcionando bem-estar (ACS; DESAI; HESSELS, 2008) gerando impostos (VERGA; SILVA, 2014). Verga e Silva (2014) destacam as contribuições de Schumpeter, apresentando o empreendedor como um promotor do desenvolvimento econômico, associando a destruição criativa. Três fatores são atribuídos aos empreendedores que colaboram para o desenvolvimento, segundo Baron e Shane (2007), divulgação dos casos de sucesso pela mídia, com isso os empreendedores ganham destaque atraindo mais pessoas para a atividade; alterações nas relações de trabalho, favorecendo um sentimento relacionado a melhores condições de trabalho; estilo de vida mais independente.

\section{Metodologia}

Para alcançar o objetivo proposto, o trabalho utiliza a metodologia quantitativa com a utilização da técnica de bibliométrica para traçar o desenvolvimento da produção científica de determinado construto (ARAÚJO, 2006). A pesquisa foi realizada no mês de agosto de 2017, na biblioteca eletrônica SPELL® - Scientific Periodicals Electronic Library, pois se trata de um repositório de artigos científicos de acesso gratuito à informação técnico-científica. Além de contemplar, em maior parte, a literatura brasileira, ao contrário de outras bases de dados que abordam em maior grau periódicos estrangeiros. Apreciar e explorar periódicos e artigos brasileiros acaba sendo uma forma de disseminar e conhecer melhor autores e suas obras.

O levantamento e seleção dos artigos se deram através da identificação de artigos com as palavras empreendedorismo, desenvolvimento e entrepreneurship, development, no título e na palavra-chave. Desta primeira seleção resultaram 57 artigos, posteriormente foram excluídos os artigos repetidos, restando então 30 artigos a serem analisados no presente estudo.

Para a análise de dados foram utilizados os softwares Excel ® 2010, para tabulação das referências, Ucinet ${ }^{\circledR}$ versão 6.569, para relacionar os nós dentro das redes e o NetDraw ${ }^{\circledR}$ versão 2.161 para criação das redes de autores. Possibilitando assim a análise dos dados que será discutida na sequência.

\section{Análise De Resultados}

Nesta seção, serão discutidos os resultados encontrados da bibliométrica realizada, refletindo primeiramente os artigos em relação a classificação do QUALIS da Capes (Gráfico 1). Foram publicados $46,5 \%$ dos trabalhos classificados no estrato B2, 23,5\% no estrato B1, $20 \%$ no estrato A2, e $10 \%$ no estrato B3. Não foram identificados trabalhos publicados na classificação A1. Notou-se que $20 \%$ dos artigos foram publicados no ano de 2016, seguido de $13,5 \%$ de artigos publicados no ano de 2011 e 2012, enquanto que nos anos de 2004 e 2006 não foram identificadas produções. 


\section{GRÁFICO 1 - Quantidade de publicações no SPELL x Qualis/Capes, de 2003 a 2017.}

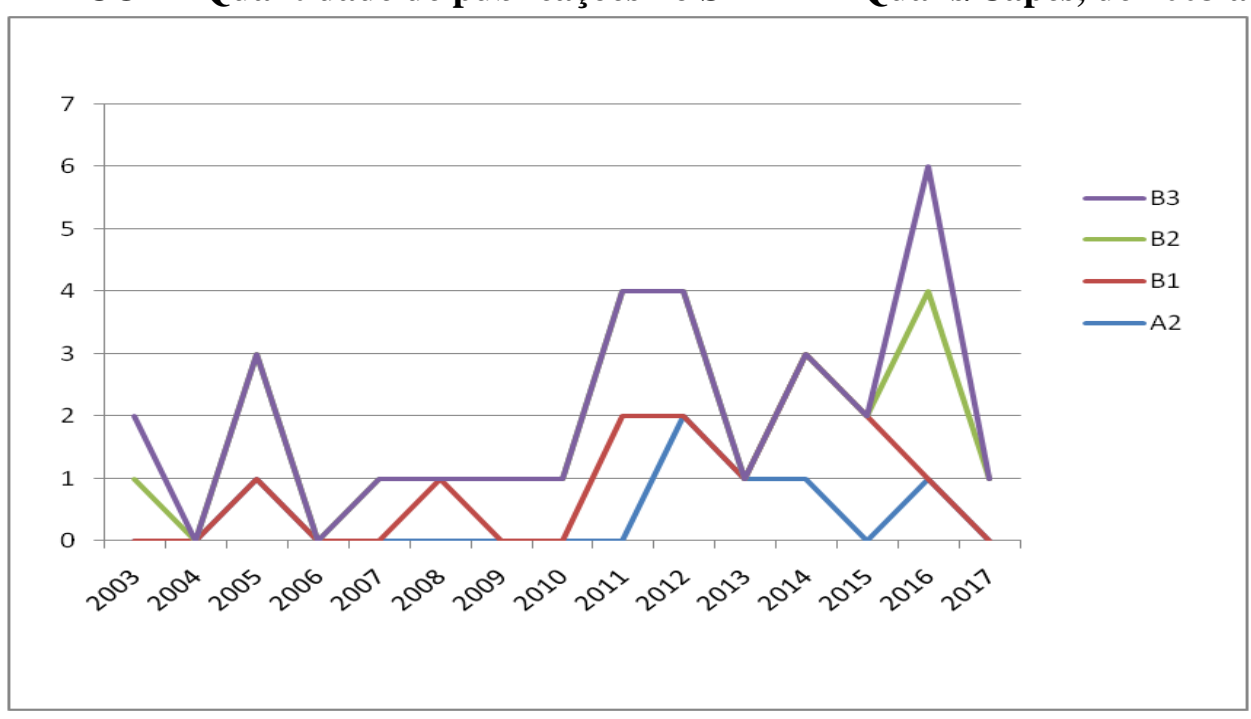

Fonte: Autor

Ao analisar os periódicos que mais publicaram neste período verificou-se que a Revista de Empreendedorismo e Gestão de Pequenas Empresas se destacou com 4 dos artigos publicados, seguido dos periódicos Revista Gestão \& Tecnologia e Revista de Administração Pública com 3 publicações cada uma, os periódicos Revista de Administração, Revista Administração em Diálogo e Desenvolvimento em Questão contemplaram 2 publicações cada uma. Os periódicos Revista de Administração e Inovação; Revista de Ciências da Administração; Revista de Administração Mackenzie; Revista Organizações em Contexto; Revista Gestão Organizacional; Revista Alcance; Revista de Administração Contemporânea; Revista Gestão \& Planejamento; International Journal of Innovation; Revista Acadêmica do Observatório de Inovação do Turismo; Revista da Micro e Pequena Empresa; Gestão \& Regionalidade; Revista Ciências Administrativas; Revista Economia \& Gestão, todas publicaram 1 artigo voltado para a temática neste período de tempo.

Foram analisados, portanto 30 artigos distribuídos em 21 periódicos, o que representa uma média de 1,42 artigos publicados por periódico. $\mathrm{O}$ empreendedorismo e $\mathrm{o}$ desenvolvimento são abordados nos artigos como empreendedorismo e desenvolvimento social, empreendedorismo e desenvolvimento sustentável, empreendedorismo e desenvolvimento econômico, ainda o intraempreendedorismo feminino, o que mostra que o empreendedorismo é analisado sob óticas distintas de geração de desenvolvimento. Porém alguns artigos não encontraram correlação entre os construtos, seria interessante realizar estudos comparativos entre regiões, países para procurar descobrir fatores que remetem a estes resultados. Foram analisadas ainda as redes de autores, conforme Figura 1, onde nota-se que entre os artigos pesquisados os autores possuem parcerias como no caso dos autores Baeta A.M.C e Rita C.S., e ainda algumas redes um pouco mais complexas como no caso dos autores Tisot S.T., Waquil P.D., Schmidt V. A rede com maior número de ligações é composta pelos cientistas Brunstein J., Desidério P.H., Cardoso Sobrinho. C.A., Martins A.A.C., Pinto, I.M.B.S. 


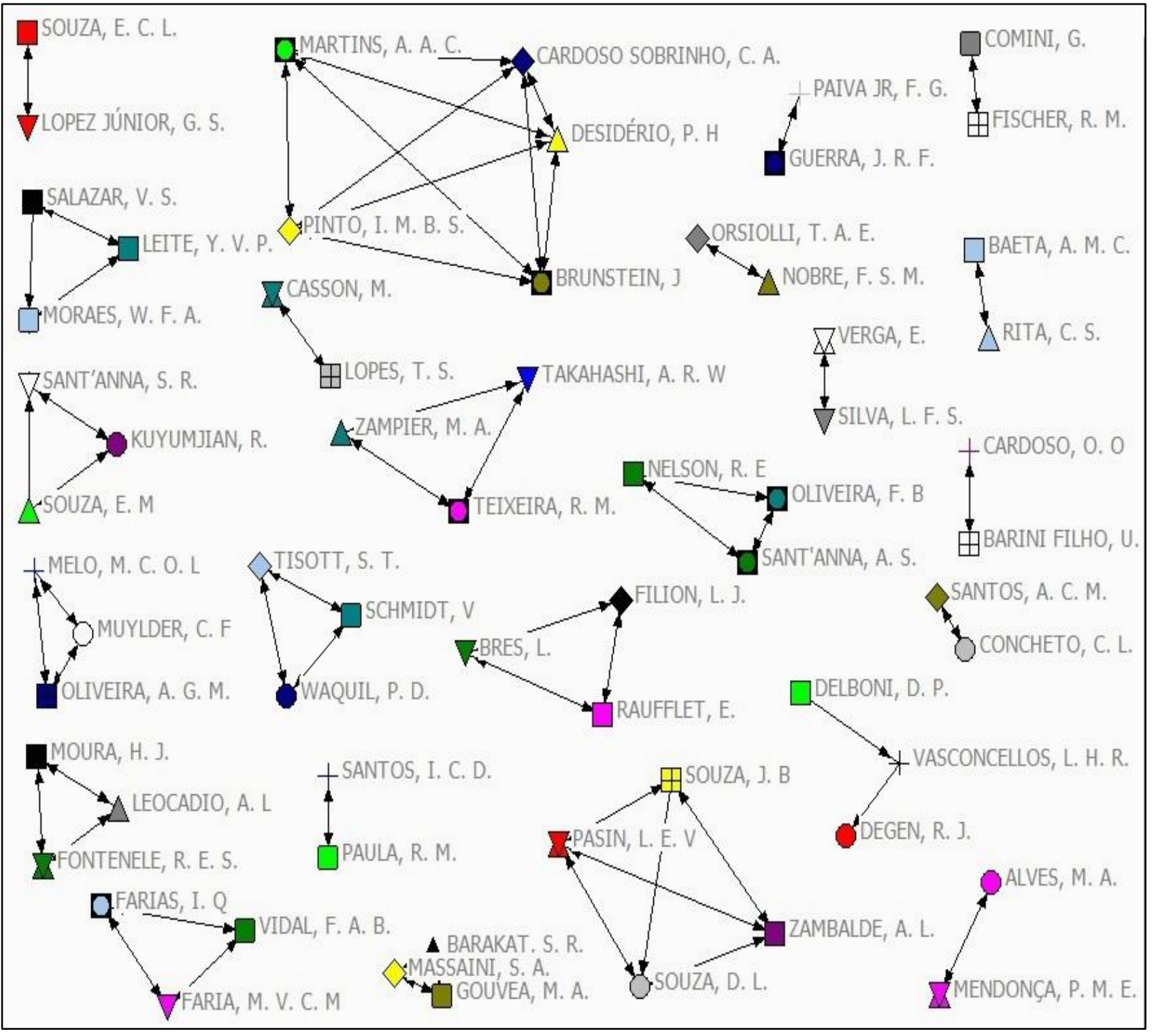

Figura 1 - Rede de autores

Fonte: Autor

Outra análise realizada foi baseada nas citações, verificando os autores e os trabalhos mais utilizados para elaboração das pesquisas dos artigos da amostra, para isso foram analisadas as referências destes artigos. $O$ cientista Louis Jacques Filion foi o mais referenciado nos artigos, apresentou 20 referências de trabalhos de sua autoria e co-autoria. Já o trabalho mais referenciado foi o livro de Joseph AloisSchumpeter "A teoria do desenvolvimento econômico". Na Tabela 1 é possível identificar melhor a análise dos autores e trabalhos mais citados. 
Tabela 1- Autores e trabalhos mais citados.

\begin{tabular}{l|l|l|l}
\hline \multicolumn{1}{c|}{ Autor } & CIT & \multicolumn{1}{c|}{ Trabalho com maior número de citações } & CIT \\
\hline FILION, L. J. & 20 & $\begin{array}{l}\text { SCHUMPETER, J. A teoria do desenvolvimento } \\
\text { econômico. São Paulo: Abril Cultural, 1982. }\end{array}$ & 6 \\
\hline SACHS, I. & 13 & $\begin{array}{l}\text { DRUCKER, P. Inovação e espírito empreendedor: } \\
\text { prática e princípios. 4.ed. São Paulo: Pioneira, 1987. }\end{array}$ & 5 \\
\hline $\begin{array}{l}\text { SCHUMPETER, J. } \\
\text { A. }\end{array}$ & 10 & $\begin{array}{l}\text { FILION, L. J. Empreendedorismo: Empreendedores e } \\
\text { proprietários-gerentes de pequenos negócios. Revista } \\
\text { de Administração, São Paulo, v. 34, n. 2, p. 5-28. 1999. }\end{array}$ & 4 \\
\hline TACHIZAWA, T. & 10 & $\begin{array}{l}\text { SEN, Amartya K. Desenvolvimento como liberdade. } \\
\text { São Paulo: Companhia das Letras, 1999. }\end{array}$ & 3 \\
\hline $\begin{array}{l}\text { SHEPHERD, D. } \\
\text { A. }\end{array}$ & 8 & $\begin{array}{l}\text { SACHS, I. Caminhos para o desenvolvimento } \\
\text { sustentável. Rio de Janeiro: Garamond, 2002. }\end{array}$ & 3 \\
\hline PORTER, M. E. & 8 & $\begin{array}{l}\text { DORNELAS, J. C. A. Empreendedorismo: } \\
\text { transformando idéias em negócios. Rio de Janeiro: } \\
\text { Campus, 2001. }\end{array}$ & 3 \\
\hline PAIVA JR, F. G. & 8 & $\begin{array}{l}\text { HALL, J. K.; DANEKE, G. A.; LENOX, M. J. } \\
\text { Sustainable development and entrepreneurship: Past } \\
\text { contributions and future directions. Journal of Business } \\
\text { Venturing, v. 25, p. 439 - 448, 2010. }\end{array}$ & 3 \\
\hline
\end{tabular}

Fonte: Autores

O autor Filion foi citado 20 vezes nos 30 artigos pesquisados, o que demostra que seus trabalhos são fundamentais quando se trata do tema empreendedorismo, sendo das 20 citações 4 foram do seu artigo 'Empreendedorismo: Empreendedores e proprietários-gerentes de pequenos negócio', as demais foram distribuídas nas suas diversas pesquisas. $\mathrm{O}$ autor Sachs foi citado 13 vezes, sendo que 3 destas foram utilizando seu livro 'Caminhos para o desenvolvimento sustentável', assim como seu outro livro 'Desenvolvimento includente, sustentável e sustentado', que não aparece na tabela, mostrando sua relevância no tema desenvolvimento sustentável. Schumpeter foi citado 10 vezes, e destas 6 foram utilizando seu trabalho 'A teoria do desenvolvimento econômico', o que representa sua importância quando se trata do empreendedorismo como forma de desenvolvimento econômico através da destruição criativa relatada pelo autor. O autor Drucker foi citado 6 vezes e destas 5 citaram seu livro 'Inovação e espírito empreendedor: prática e princípios'. 


\section{Conclusão}

A pesquisa teve como objetivo realizar um levantamento bibliométrico de pesquisas relacionadas a empreendedorismo e desenvolvimento na base de dados Spell. Com isso podese observar quais são os cientistas que pesquisam sobre os construtos e quais as visões dos mesmos. Algumas pesquisas encontraram relação negativa com o desenvolvimento (WENNEKER; THURIK, 1999; AUDRESTSCH; KEILBACH, 2004; BECK; DEMIRGUÇKUNT; LEVINE, 2005; BARROS; PEREIRA, 2008; FONTENELE; MOURA; LEOCADIO, 2011) ao contrário de outros que encontraram reações positivas entre os construtos (STEL; CARREE; THURIK, 2005; SANTOS; PAULA, 2012; CANEVER; CARRARO, 2012; ORSIOLLI; NOBRE, 2015). Segundo Henrekson e Stenkula (2009) tais diferenças nos resultados das pesquisas pode ser consequência das diferentes perspectivas/facetas do conceito utulizadas, mas também das diferentes medidas de empreendedorismo e de desenvolvimento utilizadas.

A amostra analisada foi de 30 artigos dentro do período de 2003 a 2017, sendo 46,5\% dos artigos classificados como B2 no Qualis/Capes, e não foram identificados trabalhos publicados na classificação. A Revista de Empreendedorismo e Gestão de Pequenas Empresas foi a que mais publicou sobre o tema no espaço temporal analisado, onde a média de artigos publicados por periódico foi de 1,42 artigos. O empreendedorismo é analisado sob óticas distintas de geração de desenvolvimento, nos trabalhos analisados.

Observou-se que os pesquisadores possuem pequenas redes de parcerias para suas publicações, onde as relações são poucas. $\mathrm{Na}$ análise de citações verificou-se que o cientista Louis Jacques Filion foi o mais referenciado nos artigos, já o trabalho mais referenciado foi o livro de Joseph Alois Schumpeter "A teoria do desenvolvimento econômico". A partir da análise de citações é possível identificar quais são os autores e pesquisas que são fundamentais quando o pesquisador irá tratar sobre determinado assunto. Portanto levantamentos bibliográficos são relevantes, pois auxiliam os futuros pesquisadores no momento da pesquisa, pois os mesmos poderão se direcionar para as bases especializadas sobre a temática, reduzindo a quantidade de revistas que seria necessário acessar para encontrar a mesma quantidade de artigos sobre o construto (GUEDES; BRSCHIVER, 2005). Futuras pesquisas podem realizar a análise bibliométrica em outras bases, complementando assim os resultados encontrados neste estudo.

\section{REFERÊECIAS}

ACS, Z. J.; DESAI, S.; HESSELS, J. Entrepreneurship, economic development and institutions. Small Business Economics, v. 31, n. 3, p. 219-234, set. 2008.

AGHION, P.; HOWITT, P. Growth with quality-improving innovations: an integrated framework. Handbook of Economic Growth. Harvard University, 2005.

ARAÚJO, C. A. Bibliometria: evolução histórica e questões atuais. Em Questão, Porto Alegre, v. 12, n. 1, p. 11-32, 2006.

AUDRETSCH, D. B.; KEILBACH, M. C. Entrepreneurship capital and economic performance. Regional Studies, v. 38, p. 949-959, 2004. 
AUDRETSCH, D. B.et al. Does self-employment reduce unemployment? Journal of Business Venturing, v. 23, n.6, p. 673-686, 2008.

BARINI FILHO, U.; CARDOSO, O. O. A abordagem cognitiva na formação da competência empreendedora: o caso da Odebrecht. Revista Administração em Diálogo, v. 5, n. 1, p. 6576, 2003.

BARON, R.; SHANE, S. A. Empreendedorismo: uma visão do processo. São Paulo: Thompson, 2007.

BARROS, A. A.; PEREIRA, C. M. M. A. Empreendedorismo e crescimento econômico: uma análise empírica. Revista de Administração Contemporânea, v. 12, n. 4, p. 975-993, dez. 2008.

BECK, T.; DEMIRGUÇ-KUNT, A.; LEVINE, R. SMEs, growth and poverty.NBER Working Paper Series, 11224. Cambridge: National Bureau of Economic Research, 2005.

BENNETT, J.; GOULD, M.; RABLEN, M. D. Risk attitudes and informal employment in a developing economy. IZA Journal of Labor \& Development, v. 1, n. 1, p. 1-17, 2012.

BOSZCZOWSKI, A. K.; TEIXEIRA, R. O empreendedorismo sustentável e o processo empreendedor: em busca de oportunidades de novos negócios como solução para problemas ambientais e sociais. Revista Economia \& Gestão, v. 12, n. 29, p. 141 - 168, 2012.

BUARQUE, S. C. Construindo o desenvolvimento local sustentável: metodologia de planejamento. Rio de Janeiro: Garamond, 2001.

CANEVER, M. D.; CARRARO, A. Enterprise creation and economic recovery: the case of Rio Grande do Sul. Cepal Review, 2012.

CARREE, M. A.; THURIK, A. R. Industrial structure and economic growth. In: AUDRETSCH, D. B.; THURIK, A. R. (Ed.). Innovation, industry evolution and employment. Cambridge: Cambridge University Press, p. 86-110. 1996.

DEGEN, R. J. Empreendedorismo: uma filosofia para o desenvolvimento sustentável e a redução da pobreza. Revista de Ciências da Administração, v. 10, n. 21, p. 11-30, 2008.

DORNELAS, J. C. A. Empreendedorismo: transformando ideias em negócios. Rio de Janeiro: Campus, 2001.

DOWBOR, L. Políticas nacionais de apoio ao desenvolvimento local: empreendedorismo local e tecnologias sociais. Revista de Administração Pública, v. 39, n. 2, p. 187-206, 2005.

DRUCKER, P. F. Inovação e espírito empreendedor: prática e princípios. 4.ed. São Paulo: Pioneira, 1987.

DRUCKER, P. F. Inovação e Espírito Empreendedor: práticas e princípios. São Paulo: Cengage Learning, 2008.

ELKINGTON, J.; HARTIGAN, P. The power of unreasonable people: how social entrepreneurs create markets that change the world. Boston: Harvard Business School Publishing, 2008.

\section{(1)}


FILION, L.J. Empreendedorismo: empreendedores e proprietários-gerentes de pequenos negócios. Revista de Administração, v. 34, n. 2, p.05-28, 1999.

FISCHER, R. M.; COMINI, G. Sustainable development: from responsibility to entrepreneurship. Revista de Administração, v. 47, n. 3, p. 363-369, 2012.

FONTENELE, R. E. S.; MOURA, H. J.; LEOCADIO, A. L. Capital humano, empreendedorismo e desenvolvimento: evidências empíricas nos municípios do Ceará.

Revista de Administração Mackenzie, v. 12, n. 5, art. 72, p. 182-208, 2011.

GEM 2008. Global Entrepreneurship Monitor 2008 - Empreendedorismo no Brasil. Curitiba: IBPQ, 2009.

GUEDES, V. L. S.; BORSCHIVER, S. Bibliometria: uma ferramenta estatística para a gestão da informação e do conhecimento em sistemas de informação, de comunicação e de avaliação científica e tecnológica. In: ENCONTRO NACIONAL DE CIÊNCIA DA INFORMAÇÃO, 6. 2005, Salvador. Anais..., Salvador, 2005.

HALL, J. K.; DANEKE, G. A.; LENOX, M. J. Sustainable development and Entrepreneurship: Past contributions and future directions. Journal of Business Venturing, v. 25 , p. 439 - 448, 2010.

HENREKSON, M.; JOHANSSON, D. Gazelles as job creators: a survey and interpretation of the evidence. IFN Working Paper, n. 733, 2008.

HENREKSON, M.; STENKULA, M. Entrepreneurship and public policy. IFN Working Paper. n. 804, 2009.

HISRICH, R. D.; PETERS, M. P.; SHEPHERD, D. A. Empreendedorismo. 7. ed. Porto Alegre: Bookman, 2009.

HOCKERTS, K.; WÜSTENHAGEN, R. Greening Goliaths versus emerging Davids Theorizing about the role of incumbents and new entrants in sustainable entrepreneurship. Journal of Business Venturing, v. 25, n. 5, p. 481 - 492, 2010.

KUYUMJIAN, R.; SOUZA, E. M.; SANT'ANNA, S. R. Uma análise a respeito do desenvolvimento local: o empreendedorismo social no Morro do Jaburu - Vitória (ES), Brasil. Revista de Administração Pública, v. 48, n. 6, p. 1503-1524, 2014.

LANDSTRÖM, H.; BENNER, M. Entrepreneurship research: a history of scholarly migration. Historical foundations of entrepreneurship research, p. 15-45, 2010.

LEITE, Y. V. P.; MORAES, W. F. A.; SALAZAR, V. S. Teoria adaptativa e ATLAS.ti 7: uma parceria para o desenvolvimento de framework de empreendedorismo Internacional. Revista Gestão \& Tecnologia, v. 16, n. 2, p. 153-176, 2016.

LINAAN, F.; RODRIGUEZ-COHARD, J. C.; RUEDA-CANTUCHE, J. M. Factors affecting entrepreneurial intention levels: a role for education. International Entrepreneurship and Management Journal, v. 7, n. 02, p. 195-218, 2011.

LOPES, T. S.; CASSON, M. Entrepreneurship, Brands and the Development of Global Business. Revista Organizações em Contexto, v. 3, n. 6, p. 180-213, 2007.
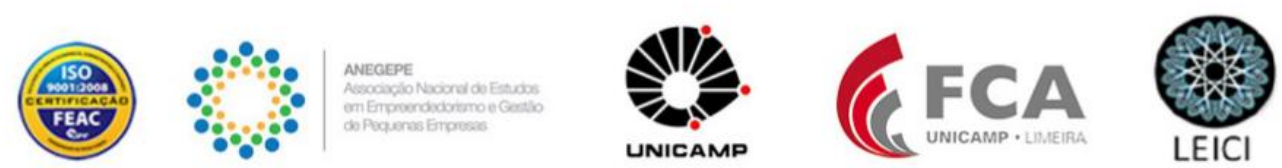
MAJID, I. A.; KOE, W-L. Sustainable Entrepreneurship (SE): A Revised Model Based on Triple Bottom Line (TBL). International Journal of Academic Research in Business and Social Sciences, v. 2, n. 6, p. 293 - 310, 2012.

MARTIN, B. R. What can bibliometrics tell us about changes in the mode of knowledge production? Prometheus, v. 29, n. 04, 2011.

MASSAINI, S. A.; BARAKAT, S. R.; GOUVÊA, M. A.; POLO, E. F. Empreendedorismo e competitividade global: uma análise multivariada de dados. Revista Gestão Organizacional, v. 5, n. 2, p. 259-271, 2012.

MENDONÇA, P. M. E.; ALVES, M. A. Institutional entrepreneurship and professionalization of the rural development of the sisal region in Brazil. Revista de Administração, v. 47, n. 3, p. 489-499, 2012.

MUELLER, S. L.; THOMAS, A. S. Culture and entrepreneurial potential: a nine country study of locus of control and innovativeness. Journal of Business Venturing, Bloomington, EUA, v. 16, p. 51-75, 2000.

NAÚDE, W. Entrepreneurship in Not a Binding Constraint on Growth and Development in the Poorest Countries. World Development, v. 39, n. 1, p. 33-41, 2011.

OCDE. Competitive Regional Clusters: National Policy Approaches. Paris: Organization for Economic Cooperation and Development, 2007.

OLIVEIRA, A. G. M.; MELO, M. C. O. L.; MUYLDER, C. F. Educação empreendedora: o desenvolvimento do empreendedorismo e inovação social em instituições de ensino superior. Revista Administração em Diálogo, v. 18, n. 1, p. 29-56, 2016.

OLIVEIRA, D. G.A Evolução Conceitual da Educação para o Empreendedorismo como um Campo Científico. Revista Alcance, v. 23, n. 4, p. 547-567, 2016.

ORSIOLLI, T. A. E.; NOBRE, F. S. M. Estudo do Empreendedorismo sob a Ótica do Desenvolvimento Sustentável. Revista de Empreendedorismo e Gestão de Pequenas Empresas, v. 4, n. 3, p. 3-36, 2015.

ORSIOLLI, T. A. E.; NOBRE, F. S. M. Empreendedorismo Sustentável e Stakeholders Fornecedores: Criação de Valores para o Desenvolvimento Sustentável . Revista de Administração Contemporânea, v. 20, n. 4, p. 502-523, 2016.

PAIVA JR, F. G.; GUERRA, J. R. F. O empreendedorismo como marco solidário na esfera do desenvolvimento. Revista Gestão \& Planejamento, v. 11, n. 2, p. 267-276, 2010.

PINTO, I. M. B. S.; BRUNSTEIN, J.; MARTINS, A. A. C.; DESIDÉRIO, P. H.; CARDOSO SOBRINHO, C. A. Systematic Review of the Literature Social Entrepreneurship and Skills Development: An Analysis of Past 10 years. International Journal of Innovation, v. 4, n. 1, p. 33-45, 2016.

RAUFFLET, E.; BRES, L.; FILION, L. J. Desenvolvimento sustentável e empreendedorismo. Revista de Empreendedorismo e Gestão de Pequenas Empresas, v. 3, n. 1, p.3 - 32, 2014. 
REYNOLDS, P. D.; STOREY, D. J.; WESTHEAD, P. Cross national comparison of the variation on the new firm formation rates. Regional Studies, v. 28, n. 4, p. 443-456, 1994.

RITA, C. S.; BAETA, A. M. C. Desenvolvimento regional e empreendedorismo internacional: - Como atuam as incubadoras no Brasil? Revista Gestão \& Tecnologia, v. 5, n. 2, p. 1-14, 2005.

SACHS, I. Caminhos para o desenvolvimento sustentável. Rio de Janeiro: Garamond, 2002.

SANCHEZ, J. C. University training for entrepreneurial competencies: its impact on intention of venture creation. International Entrepreneurship and Management Journal, v. 07, n.02, p. 239-254, 2011.

SANT'ANNA, A. S.; NELSON, R. E.; OLIVEIRA, F. B. Empreendedorismo e o desenvolvimento do turismo na cidade de Tiradentes. Revista Acadêmica do Observatório de Inovação do Turismo, v. 6, n. 1, art. 4, p. 1-27, 2011.

SANTOS, A. C. M.; CONCHETO, C. L. Empreendedorismo social: implementação de um modelo de desenvolvimento sustentável no contexto socioambiental de Campo Limpo Paulista e região. Revista da Micro e Pequena Empresa, v. 3, n. 1, p. 95-117, 2009.

SANTOS, I. C. D.; PAULA, R. M. A especialização tecnológica local como indutora do empreendedorismo e do desenvolvimento regional: o caso do Vale da Eletrônica Brasileiro. Gestão \& Regionalidade, v. 28, n. 82, p. 65-82, 2012.

SARFATI, G. Estágios de desenvolvimento econômico e políticas públicas de empreendedorismo e de micro, pequenas e médias empresas (MPMEs) em perspectiva comparada: os casos do Brasil, do Canadá, do Chile, da Irlanda e da Itália. Revista de Administração Pública, v. 47, n. 1, p. 25-48, 2013.

SEN, A. K. Desenvolvimento como liberdade. São Paulo: Companhia das Letras, 1999.

SCHUMPETER, J. A teoria do desenvolvimento econômico. São Paulo: Abril Cultural, 1982.

SHANE, S.; VENKATARAMAN, S.The promise of entrepreneurship as a field of research. Academy of Management Review, v. 25. n. 1. p. 217-226, 2000.

SLEVIN, D. P.; COVIN, J. G. Juggling entrepreneurial style and organizational structure. MIT Sloan Management Review, v. 31, n. 2, p. 43, 1990.

SOUZA, E. C. L.; LOPEZ JÚNIOR, G. S. Empreendedorismo e Desenvolvimento: uma Relação em Aberto. Revista de Administração e Inovação, v. 8, n. 3, art. 63, p. 120-140, 2011.

SOUZA, D. L.; SOUZA, J. B.; PASIN, L. E. V.; ZAMBALDE, A. L. Empreendedorismo e Desenvolvimento Local: Uma Análise do Programa Microempreendedor Individual em Minas Gerais. Desenvolvimento em Questão, v. 14, n. 37, p. 262-292, 2016.

STEL, A.V; CARREE, M.; THURIK, A. R.The effect of entrepreneurial activity on national economic growth. Small Business Economics, v. 24, n.3, p. 311-321, 2005. 
TILLEY, F.; YOUNG, W. Sustainability Entrepreneurs: Could they be the True Wealth Generator of the Future? Greener Management International, v. 55, p. 79 - 92, 2009.

TISOTT, S. T.; SCHMIDT, V.; WAQUIL, P. D. Atividade Florestal e o Desenvolvimento Socioeconômico em Três Lagoas e Região: Uma Análise Baseada na Abordagem de Cluster. Desenvolvimento em Questão, v. 15, n. 38, p. 228-260, 2017.

VASCONCELLOS, L. H. R.; DELBONI, D. P. Empreendedorismo e precarização do trabalho: o desenvolvimento e a aplicação de uma estrutura para análise de empreendedoras no estado de São Paulo. Revista de Empreendedorismo e Gestão de Pequenas Empresas, v. 4, n. 1, p. 54-78, 2015.

VERGA, E.; SILVA, L. F. S. Empreendedorismo: evolução histórica, definições e abordagens. Revista de Empreendedorismo e Gestão de Pequenas Empresas, v. 3, n. 3, p. 3-30, 2014.

VIDAL, F. A. B.; FARIAS, I. Q.; FARIA, M. V. C. M. Empreendedorismo social promovendo a inserção cidadâ de famílias de baixa renda: o caso da Fundesol/CE - Agência de desenvolvimento local e sócio economia solidária. Revista Gestão \& Tecnologia, v. 5, n. 2, p. 1-17, 2005

VILLEGAS, R. V. Hacia una universidad con espíritu empresarial. Revista Ciências Administrativas, v. 9, n. 2, p. 119-131, 2003.

ZAMPIER, M. A.; TAKAHASHI, A. R. W.; TEIXEIRA, R. M. Intraempreendedorismo feminino e desenvolvimento de competências empreendedoras: um estudo de caso com professoras de Programas de Mestrado e Doutorado em Administração de Curitiba-PR.

Revista Economia \& Gestão, v. 11, n. 25, p. 34-61, 2011.

WENNEKERS, S.; THURIK, R. Linking entrepreneurship and economic growth. Small Business Economics, v. 13, n. 1, p. 27-55, 1999. 